Original Research Paper

\title{
Detection of Soil Total Nitrogen, Phosphorus and Potassium Content Based on the Spectral Information of Citrus Canopy
}

\author{
${ }^{1,2,3}$ Lin Yunshuo, ${ }^{1,2,3}$ Li Zhen, ${ }^{1,2,3}$ Lv Shilei, ${ }^{1,2,3}$ Huang Heqing and ${ }^{1,2,3} \mathrm{Hu}$ Jiapei \\ ${ }^{1}$ College of Electronic Engineering and Artificial Intelligence, South China Agricultural University, Guangzhou 510642, China \\ ${ }^{2}$ Division of Citrus Machinery, China Agriculture Research System, Guangzhou 510642, China \\ ${ }^{3}$ Guangdong Engineering Research Center for Monitoring Agricultural Information, Guangzhou 510642, China
}

\section{Article history}

Received: 24-02-2020

Revised: 27-03-2020

Accepted: 16-04-2020

Corresponding Authors:

Li Zhen

${ }^{1}$ College of Electronic

Engineering and Artificial

Intelligence, South China

Agricultural University, Guangzhou 510642, China;

${ }^{2}$ Division of Citrus Machinery,

China Agriculture Research

System, Guangzhou 510642,

China;

${ }^{3}$ Guangdong Engineering

Research Center for Monitoring

Agricultural Information,

Guangzhou 510642, China

Email: lizhen@scau.edu.cn

\begin{abstract}
The content of total nitrogen, phosphorus and potassium in the soil is an important basis for calculating the best fertilization amount and realizing the reasonable fertilization of the orange planting soil in time and accurately. In this research, hyper-spectral technology is applied to detect the three soil nutrient elements in the cultivated soil of citrus trees. Four spectral bands with central wavelengths of 660, 780, 870 and $970 \mathrm{~nm}$ and width of $20 \mathrm{~nm}$ are selected to measure the spectral reflectance of the potted kumquats canopy by hand-held spectrometer. At the same time, the content of total nitrogen, phosphorus and potassium in the cultivated soil of kumquat is determined using traditional methods. The correlation between the spectral information of kumquat canopy and the content of soil nutrient elements is analyzed by correlation coefficient method. The prediction model of soil nutrient element content based on the spectral information is established by multiple linear regression method. The results showed that the total potassium content of soil is significantly correlated with the spectral reflectance at $660 \mathrm{~nm}$ wave band and significantly correlated with the spectral indexes of $\mathrm{R}_{660} / \mathrm{R}_{780}, \mathrm{R}_{660} / \mathrm{R}_{870}$ and $\mathrm{R}_{660} / \mathrm{R}_{970} . R^{2}$ of the prediction model of total potassium content established on the basis of spectral reflectance and ratio spectral index of the selected band is 0.756 and 0.857 respectively, which shows good prediction effect of the model. There is no significant correlation between the spectral reflectance and ratio spectral index of the selected band towards the total soil nitrogen and phosphorus content and it cannot be used for the rapid measurement of total nitrogen and phosphorus content. Further study is needed to select suitable spectral band and spectral index.
\end{abstract}

Keywords: Citrus, Spectrometer, Nutrient Elements, Spectral Analysis, Fine Agriculture

\section{Introduction}

China is a big country of citrus production, with the largest planting area and output in the world ( $\mathrm{Li}, 2011)$. Nitrogen $(\mathrm{N})$, phosphorus $(\mathrm{P})$ and potassium $(\mathrm{K})$ in the soil of citrus cultivation area are the main nutrient elements for the growth and development of citrus. The content of total nitrogen, phosphorus and potassium is the key index to evaluate soil quality and calculate the amount of fertilizer.

Although the results of traditional chemical analysis methods of soil total nitrogen, phosphorus and potassium content are relatively accurate (Song et al., 2012), the long measurement cycle and high cost cannot achieve rapid, large-scale and real-time monitoring. The spectral analysis method based on visible light or near-infrared has the advantages of fast detection speed, low cost and no damage to the sample, which provides a new and effective way for the detection of soil parameters. Ding et al. (2011) found that $570 \mathrm{~nm}, 600 \mathrm{~nm}$ and $610 \mathrm{~nm}$ spectral bands have good indicators for soil organic matter and fertility. Musadji et al. (2012) found that the spectra near $700 \mathrm{~nm}$ and $1050 \mathrm{~nm}$ were closely related to the content of soil organic matter and clay minerals. Chen et al. (2008) showed that the near-infrared spectroscopy technology can accurately detect the total nitrogen content and roughly estimate the total P in soil. Yi et al. (2011) found that near-infrared spectroscopy can be used to predict the 
content of $\mathrm{Fe} / \mathrm{Mn} / \mathrm{Zn}$ in purple soil of citrus orchard. Other studies have also shown that spectral techniques can be used to detect soil fertility (Xie et al., 2004; Li et al., 2012; Wamelink et al., 2018; Sophie et al., 2019). On the basis of theoretical research, the researchers developed a rapid soil parameter measurement equipment and system based on spectral technology, which further improved the efficiency of soil parameter measurement and reduced the detection cost ( $\mathrm{Li}$ et al., 2007; $\mathrm{Li}$ and $\mathrm{Li}$, 2008; Zheng et al., 2009).

Even though the spectral analysis method can directly detect the soil parameters, it is difficult to directly obtain the spectral characteristics of the soil under the vegetation coverage when the plant coverage area is large. In the similar natural environment, the difference of plant growth reflects the difference of soil nutrients. Therefore, the soil parameters can be calculated by measuring the plant canopy spectrum and soil fertility can be measured indirectly. Pan et al. (2010) showed that the total nitrogen content of soil was negatively correlated with the reflectance of cotton canopy at 400$700 \mathrm{~nm}$ band and positively correlated with the reflectance at 700-1300 $\mathrm{nm}$ band. Xu et al. (2007) showed that the normalized spectral index of rice canopy remote sensing Hyperspectral Information had significant correlation with soil nutrients such as soil available $\mathrm{N}$ and organic matter.

A new method is proposed in this paper to measure the content of soil nutrient elements quickly and indirectly by measuring the spectral reflectance index of citrus canopy. The purpose of this study is to investigate the correlation between the canopy spectra of citrus and the contents of total nitrogen (TN), total phosphorus (TP) and total potassium (TK) in soil. The prediction model of TN, TP and TK content in soil based on the spectral information of citrus canopy will be established. The rapid measurement methodology of soil nutrient element content based on the spectral information of citrus canopy will be studied.

In this article, methods of soil sample collection and soil nutrient content measurement is firstly presented. Next, method of citrus canopy spectral data collection is introduced. In the third step, we presented that The Pearson correlation coefficient is used to study the correlation between the spectral reflectance of four bands and six ratio spectral indices and the contents. Also, we used the method of multiple linear regressions, the spectral reflectance of four bands and the spectral index of six ratios in each data set of the modeling group are taken as independent variables. In the after, the correlation analysis is carried out both between the soil nutrient element content and the citrus tree canopy spectral reflectance and between the ratio spectral index and soil nutrient element content.

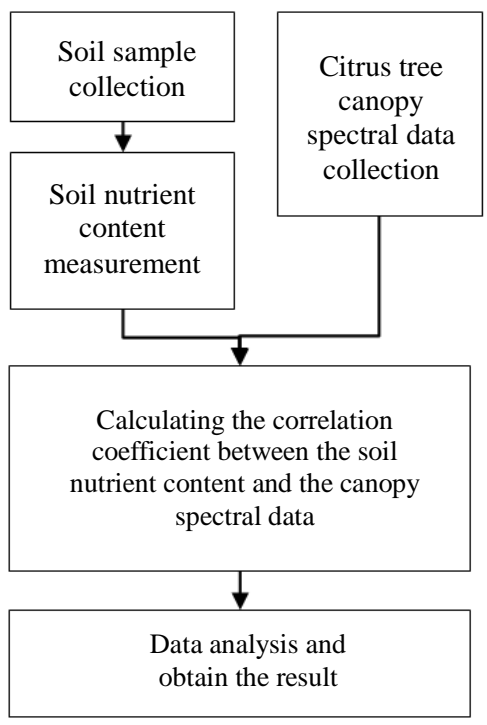

Fig. 1: The flowchart of this research

The flowchart of this research is as shown in Fig. 1.

\section{Materials and Methods}

\section{Soil Sample Collection and Analysis}

The soil samples and spectral data of this study are collected from March to May in the experimental citrus orchard of the Mechanical Research Office of the national citrus industry technology system of South China Agricultural University. In this experimental citrus orchard, 30 potted kumquats were selected in the spring shoot stage with good growth. Two samples were collected from the planting soil of each citrus orchard, 60 soil samples in total. At the same time of collecting soil samples, the canopy reflectance spectrum of the orange tree was measured to ensure the synchronization of soil samples and canopy spectral information collection in time. The two soil sampling points corresponding to each Kumquat tree are respectively $180^{\circ}$ on both sides of the middle point of the main Kumquat tree and $5-10 \mathrm{~cm}$ from the middle point of the main Kumquat tree. During sampling, weeds, dead branches and leaves on the surface of the soil were removed first and the soil $5-10 \mathrm{~cm}$ below the surface of the ground shall be taken as the experimental soil sample and the mass of each sample is about $1 \mathrm{~kg}$. Grind the soil sample properly after natural air drying, remove the sundries and place it in a plastic film bag for sealing and preservation.

The traditional analysis of TN, TP and TK contents in soil was carried out in the School of Resources and Environment, South China Agricultural University. Kelvin-distillation titration is used for TN determination, sodium hydroxide melting-molybdenum 
antimony anti colorimetric method is used for TP determination and sodium hydroxide melting-flame atomic absorption spectrophotometry is used for TK determination. The main equipment used is the Z-2300 flame atomic absorption spectrophotometer of Hitachi. After the determination of soil parameters, average the parameters of two soil samples from the same citrus as the nutrient element content of the citrus planting soil.

\section{Data Collection of Reflection Spectrum of Citrus Canopy}

When (Yi et al., 2010) measured the nitrogen content in the leaves of Jincheng, it was found that there was a significant difference between the reflectance of each nitrogen treatment in 750-1000 nm. Therefore, in this study, four bands with the central wavelengths of $660,780,870$ and $970 \mathrm{~nm}$ and the width of $20 \mathrm{~nm}$ were selected from the visible and nearinfrared bands to measure the spectral reflectance of citrus canopy to the above four bands, which were labeled $\mathrm{R}_{660}, \mathrm{R}_{780}, \mathrm{R}_{870}$ and $\mathrm{R}_{970}$ respectively. The spectrum was measured by a hand-held spectrometer developed by Oklahoma State University. The main characteristics of the equipment are as follows: a. the measurement range is $480-1200 \mathrm{~nm}$ and the sampling interval is $10 \mathrm{~nm}$; b. active light source, optical modulation and demodulation, double light differential detection and other technologies are used to effectively eliminate the influence of natural light intensity on the measurement results; c. changing the installed filter and light-emitting element can change the measured spectral band; d. The normalized spectral reflectance is output through RS-232 interface with $45^{\circ}$ luminous angle and $25^{\circ}$ visual angle of the photodetector. The luminous lens is parallel to the axis of the detection filter, the distance between the axes is about $5 \mathrm{~cm}$ and the height difference of the vertical axis is about $3 \mathrm{~cm}$.

The spectral measurement method of this study is shown in Fig. 2 and the spectral determination time is 10:00-14:00. The distance from the light probe of the spectrometer to the ground is the height corresponding to the maximum diameter $\left(D_{\max }\right)$ of the canopy of each citrus. The light-emitting probe of the spectrometer faces the citrus horizontally, with a distance of $30 \mathrm{~cm}$ from the outer edge of the citrus canopy. Samples are taken in the East, South and North directions of each citrus respectively. Each sampling point is measured three times, with time interval of each measurement no less than 20s. The average value of nine measurements is taken as the spectral reflection value of the citrus canopy. Because the detector angle of the spectrometer is small and the citrus branches and leaves were dense, the main measurement background is the citrus leaves (Wang et al., 2010).

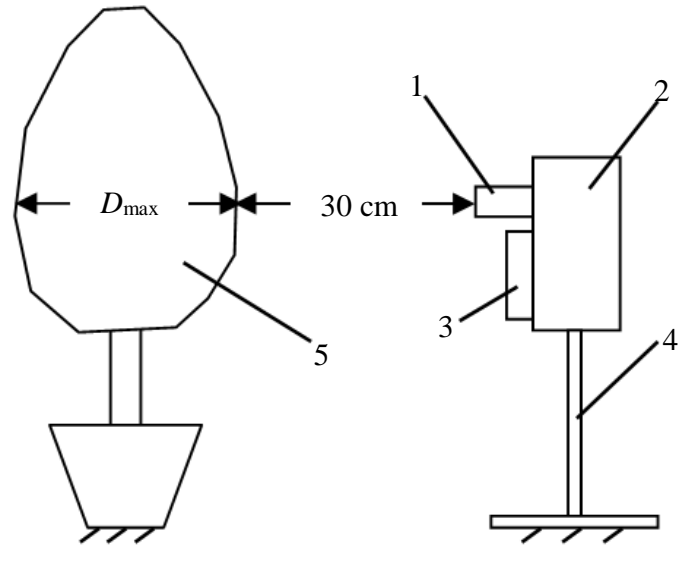

Fig. 2: Schematic diagram of spectral data acquisition; 1. Optical probe and lens 2. Spectrometer host 3. Luminous parts 4. Support 5. Citrus canopy

\section{Data Analysis Method}

After data collection, a total of 30 data sets are obtained, each data set is corresponding to a citrus and its cultivated soil. In each data set, the data includes: (1) The spectral reflectance of a single citrus tree canopy at $660\left(\mathrm{R}_{660}\right), \quad 780\left(\mathrm{R}_{780}\right), \quad 870\left(\mathrm{R}_{870}\right)$ and 970(R970) nm; (2) The spectral indexes of $R_{660} / R_{780}$, $\mathrm{R}_{660} / \mathrm{R}_{870}, \mathrm{R}_{660} / \mathrm{R}_{970}, \mathrm{R}_{780} / \mathrm{R}_{870}, \mathrm{R}_{780} / \mathrm{R}_{970}$ and $\mathrm{R}_{870} / \mathrm{R}_{970}$ of single citrus canopy; (3) TN, TP and TK contents of the cultivated soil where the citrus tree is located. In the 30 data sets, 22 were randomly selected as the modeling group and the remaining 8 as the validation group. SPSS (version 14.0, SPSS Inc, Chicago, USA) software is used for data analysis as follows:

\section{Correlation Analysis}

The Pearson correlation coefficient $(r)$ is used to study:

a. The correlation between the spectral reflectance of four bands and the contents of TN, TP and TK in soil

b. The correlation between the six ratio spectral indices and the contents of TN, TP and TK in soil

Where, $0.8<|r|<1$ represents a strong correlation, $0.6<|r|<0.8$ represents correlation, $0.4<|r|<0.6$ represents moderate correlation, $0.2<|r|<0.4$ represents weak correlation and $0.0<|r|<0.2$ represents extremely weak correlation.

\section{Multiple Linear Regression}

The method of multiple linear regressions is used to study:

a. To obtain the prediction model of soil nutrient element content based on spectral reflectance. The spectral reflectance of four bands in each data set of 
the modeling group are taken as independent variables. TN, TP and TK contents of soil are dependent variables. Through the significance test, the applicability of the selected spectrum to the prediction of soil total nitrogen, phosphorus and potassium content is analyzed. The spectral information in each data set of the validation group is substituted into the prediction model and the test standard deviation between the predicted value and the actual value of $\mathrm{TN}, \mathrm{TP}$ and $\mathrm{TK}$ content is calculated. By comparing the difference between the prediction standard deviation and the detection standard deviation, the prediction ability of the detection model is tested (Satapute et al., 2019)

b. To obtain the prediction model of soil nutrient element content based on ratio spectral index. The spectral index of six ratios in each data set of the modeling group are taken as independent variables. TN, TP and TK contents of soil are dependent variables. Through the significance test, the applicability of the selected spectral index to the prediction of soil total nitrogen, phosphorus and potassium content is analyzed. The spectral index in each data set of the validation group is substituted into the prediction model and the test standard deviation between the predicted value and the actual value of TN, TP and TK content is calculated

\section{Result and Analysis}

\section{Correlation Analysis of Spectral Reflectance and Soil Nutrient Element Content}

The correlation analysis results between the spectral reflectance of $\mathrm{R}_{660}, \mathrm{R}_{780}, \mathrm{R}_{870}$ and $\mathrm{R}_{970}$ as well as TN, TP and TK contents are shown in Table 1.
According to Table 1, the correlation coefficient between $R_{660}$ and TK content is -0.661 . Sig value of the significant analysis result is less than 0.001 , which is significantly correlated at the level of 0.01 . The results show that the correlation between total potassium content and spectral reflectance at $660 \mathrm{~nm}$ was significant. The sig value of other spectral reflectance and soil nutrient element content is greater than 0.05 , indicating that the correlation between other spectral reflectance and soil nutrient element content is not significant.

\section{Correlation Analysis of Ratio Spectral Index and Soil Nutrient Element Content}

The correlation analysis results between the spectral reflectance of $\mathrm{R}_{660} / \mathrm{R}_{780}, \mathrm{R}_{660} / \mathrm{R}_{870}, \mathrm{R}_{660} / \mathrm{R}_{970}, \mathrm{R}_{780} / \mathrm{R}_{870}$, $\mathrm{R}_{780} / \mathrm{R}_{970}$ and $\mathrm{R}_{870} / \mathrm{R}_{970}$ and TN, TP and TK contents is shown in Table 2.

According to Table 2, the correlation coefficients between $\mathrm{R}_{660} / \mathrm{R}_{780}, \mathrm{R}_{660} / \mathrm{R}_{870}$ and $\mathrm{R}_{660} / \mathrm{R}_{970}$ and soil $\mathrm{TK}$ content are $-0.663,-0.631$ and -0.645 respectively and the sig value of significance analysis is less than 0.001 . The correlation is significant at 0.01 level, indicating that the total potassium content in soil is significantly related to the above three ratio spectral indexes. The sig value of other ratio spectral indexes and soil nutrient element content is greater than 0.05 , indicating that the correlation between other spectral indexes and soil nutrient element content is not significant.

\section{Prediction Model of Soil Nutrient Element Content Based on Spectral Reflectance}

The prediction model of TN, TP and TK content in soil is established based on the spectral reflectance of $\mathrm{R}_{660}, \mathrm{R}_{780}, \mathrm{R}_{870}$ and $\mathrm{R}_{970}$ and the prediction ability of the model was tested. The results are shown in Table 3:

Table 1: Result of correlation analysis between spectral reflectance and soil nutrient element content

\begin{tabular}{|c|c|c|c|c|c|c|}
\hline \multirow{2}{*}{$\begin{array}{l}\text { Spectral } \\
\text { band }\end{array}$} & \multicolumn{2}{|c|}{ Relationship of TN content } & \multicolumn{2}{|c|}{ Relationship of TP content } & \multicolumn{2}{|c|}{ Relationship of TK content } \\
\hline & Correlation coefficient & Sig value & Correlation coefficient & Sig value & Correlation coefficient & Sig value \\
\hline $\mathrm{R}_{660}$ & -0.332 & 0.073 & -0.096 & 0.613 & -0.661 & $0.000^{* *}$ \\
\hline $\mathrm{R}_{780}$ & -0.079 & 0.677 & -0.035 & 0.855 & -0.249 & 0.184 \\
\hline $\mathrm{R}_{870}$ & -0.169 & 0.372 & 0.007 & 0.970 & -0.346 & 0.061 \\
\hline $\mathrm{R}_{970}$ & -0.145 & 0.445 & 0.058 & 0.761 & -0.321 & 0.084 \\
\hline
\end{tabular}

** means that the results of significance analysis are significantly correlated at the level of 0.01

Table 2: Result of correlation analysis between spectral ration index and soil nutrient element content

\begin{tabular}{|c|c|c|c|c|c|c|}
\hline \multirow{2}{*}{$\begin{array}{l}\text { Ratio spectral } \\
\text { index }\end{array}$} & \multicolumn{2}{|c|}{ Relationship of TN content } & \multicolumn{2}{|c|}{ Relationship of TP content } & \multicolumn{2}{|c|}{ Relationship of TK content } \\
\hline & Correlation coefficient & Sig value & Correlation coefficient & Sig value & Correlation coefficient & Sig value \\
\hline $\mathrm{R}_{660} / \mathrm{R}_{780}$ & -0.326 & 0.079 & -0.106 & 0.579 & -0.663 & $0.000^{* *}$ \\
\hline $\mathrm{R}_{660} / \mathrm{R}_{870}$ & -0.316 & 0.089 & -0.121 & 0.523 & -0.631 & $0.000^{* * *}$ \\
\hline $\mathrm{R}_{660} / \mathrm{R}_{970}$ & -0.320 & 0.085 & -0.159 & 0.402 & -0.645 & $0.000^{* * *}$ \\
\hline $\mathrm{R}_{780} / \mathrm{R}_{870}$ & 0.198 & 0.295 & -0.008 & 0.968 & 0.340 & 0.066 \\
\hline $\mathrm{R}_{780} / \mathrm{R}_{970}$ & 0.153 & 0.420 & -0.070 & 0.712 & 0.286 & 0.125 \\
\hline $\mathrm{R}_{870} / \mathrm{R}_{970}$ & -0.043 & 0.821 & -0.244 & 0.194 & -0.007 & 0.970 \\
\hline
\end{tabular}

** means that the results of significance analysis are significantly correlated at the level of 0.01 
Lin Yunshuo et al. / American Journal of Biochemistry and Biotechnology 2020, 16 (2): 177.183 DOI: 10.3844/ajbbsp.2020.177.183

Table 3: Prediction model of soil nutrient element content based on spectral reflectance

\begin{tabular}{|c|c|c|c|c|c|c|c|c|c|}
\hline \multirow[b]{2}{*}{$\begin{array}{l}\text { Dependent } \\
\text { Variable }\end{array}$} & \multicolumn{9}{|c|}{ Coefficient of each variable } \\
\hline & $\mathrm{R}_{660}$ & $\mathrm{R}_{780}$ & $\mathrm{R}_{870}$ & R970 & Constant & $R^{2}$ & $\begin{array}{l}\text { Prediction standard } \\
\text { derivation }\end{array}$ & $\begin{array}{l}\text { Test standard } \\
\text { deviation }\end{array}$ & $\begin{array}{l}\text { Sig } \\
\text { value }\end{array}$ \\
\hline $\mathrm{TN}$ & -4.429 & 3.371 & -15.293 & 7.950 & 1.301 & 0.217 & 0.416 & 0.354 & 0.355 \\
\hline $\mathrm{TP}$ & -7.480 & -1.014 & -16.790 & 20.548 & 3.382 & 0.256 & 0.616 & 0.490 & 0.875 \\
\hline TK & -90.788 & -13.352 & -2.588 & 41.705 & 24.531 & 0.756 & 1.217 & 1.069 & $0.005^{* *}$ \\
\hline
\end{tabular}

** means that the results of significance analysis are significantly correlated at the level of 0.01

Table 4: Prediction model of soil nutrient element content based on ratio spectral index

\begin{tabular}{|c|c|c|c|c|c|c|c|c|c|c|c|}
\hline \multirow{2}{*}{$\begin{array}{l}\text { Dependent } \\
\text { variable }\end{array}$} & \multicolumn{8}{|c|}{ Coefficient of each variable } & \multirow{2}{*}{$\begin{array}{l}\text { Prediction } \\
\text { standard } \\
\text { derivation }\end{array}$} & \multirow{2}{*}{$\begin{array}{l}\text { Test } \\
\text { standard } \\
\text { deviation }\end{array}$} & \multirow{2}{*}{$\begin{array}{l}\text { Sig } \\
\text { value }\end{array}$} \\
\hline & $\mathrm{R}_{660} / \mathrm{R}_{780}$ & $\mathrm{R}_{660} / \mathrm{R}_{870}$ & $\mathrm{R}_{660} / \mathrm{R}_{970}$ & $\mathrm{R}_{780} / \mathrm{R}_{870}$ & $\mathrm{R}_{780} / \mathrm{R}_{970}$ & $\mathrm{R}_{870} / \mathrm{R}_{970}$ & Constant & $R^{2}$ & & & \\
\hline $\mathrm{TN}$ & 0.958 & -8.182 & 9.360 & -1.911 & 2.039 & -12.489 & 11.589 & 0.467 & 0.458 & 0.351 & 0.777 \\
\hline TP & 34.682 & 35.760 & -39.015 & 0.510 & 0.019 & 2.959 & -3.073 & 0.408 & 0.619 & 0.488 & 0.800 \\
\hline TK & -3.828 & 43.004 & -49.135 & -13.709 & 11.585 & -55.878 & 85.951 & 0.857 & 1.288 & 1.050 & $0.003^{* *}$ \\
\hline
\end{tabular}

According to Table 3, the determination coefficient of the model for predicting the total potassium content of soil based on the spectral reflectance is the highest $\left(R^{2}=\right.$ 0.756 ) and the sig value of the significance analysis result is 0.005 . It indicates that the model independent variable and dependent variable have significant correlation. In TK prediction model, the $\mathrm{R}_{660}$ band reflectance takes the largest weight, which is consistent with the most significant correlation between $\mathrm{R}_{660}$ band reflectance and soil TK content in Table 1. The model test results show that the standard deviation of TK content prediction model based on spectral reflectance is close to the test standard deviation. The model can predict soil TK content optimally.

\section{Prediction Model of Soil Nutrient Element Content Based on Ratio Spectral Index}

The prediction model of TN, TP and TK content in soil is established based on six ratio spectral indexes of $\mathrm{R}_{660} / \mathrm{R}_{780}, \mathrm{R}_{660} / \mathrm{R}_{870}, \mathrm{R}_{660} / \mathrm{R}_{970}, \mathrm{R}_{780} / \mathrm{R}_{870}, \mathrm{R}_{780} / \mathrm{R}_{970}$ and $\mathrm{R}_{870} / \mathrm{R}_{97}$ and the prediction ability of the model was tested. The results are shown in Table 4.

According to Table 4, the determination coefficient of the model for predicting soil total potassium content based on the ratio spectral index is the highest $\left(R^{2}=0.857\right)$. The Sig value of significance analysis is 0.003 , which indicates that there is a significant correlation between the ratio spectral index and TK content. Although the determination coefficients of TP and TK prediction models are 0.467 and 0.408 respectively, Sig values of significance analysis results are 0.777 and 0.800 respectively and the correlation between independent variables and dependent variables is not significant. The model test results show that the standard deviation of TK content prediction model based on ratio spectral index is close to the test standard deviation. The model can predict soil TK content better.

\section{Discussion}

It was found that the correlation between the selected spectral band and ratio spectral index and soil $\mathrm{TN}$ and TP content, as well as the determination coefficient of the prediction model are both low. As a result, the selected spectral band and ratio spectral index cannot be used for the rapid measurement of total nitrogen and phosphorus content.

Further research will include:

1. Selecting more suitable spectral band and spectral index to accurately predict TN and TP content in soil

2. More citrus varieties should be included in this study as the spectral measurement object rather except for the kumquat tree

Analyzing the indication effect of spectral information of citrus canopy on soil total nitrogen, total phosphorus and total potassium content in different growth periods.

\section{Conclusion}

In this study, the spectral reflectance of citrus canopy is applied to indirectly measure the potting soil nutrient content. It is a new method to detect the content of soil nutrients. The correlation between at 660, 780, 870 and $970 \mathrm{~nm}$ and the spectral indexes of $\mathrm{R}_{660} / \mathrm{R}_{780}, \mathrm{R}_{660} / \mathbf{R}_{870}$, $\mathrm{R}_{660} / \mathrm{R}_{970}, \mathrm{R}_{780} / \mathrm{R}_{870}, \mathrm{R}_{780} / \mathrm{R}_{970}, \mathrm{R}_{870} / \mathrm{R}_{970}$ and the contents of TN, TP and TK is analyzed. Two kinds of prediction models of soil nutrient element content based on the spectral reflectance and ratio spectral indexes of citrus canopy are established. The results show that:

1. Soil TK content is significantly correlated with $660 \mathrm{~nm}$ spectral reflectance and $\mathrm{R}_{660} / \mathrm{R}_{780}, \mathrm{R}_{660} / \mathrm{R}_{870}$ and $\mathrm{R}_{660} / \mathrm{R}_{970}$

2. The determination coefficients of TK content prediction model based on spectral reflectance and 
ratio spectral index are 0.756 and 0.857 respectively. The model has a high correlation between independent variables and dependent variables and the prediction effect is optimal. The results show that the method based on the spectral information of citrus canopy is feasible

\section{Acknowledgement}

The authors would like to acknowledge the financial support from the National Science Foundation of China (Grant No. 31971797 and 61601189), Special Fund of Modern Technology System of Agricultural Industry (Grant No. CARS-26), Science and Technology Program of Guangzhou, China (Grant No. 201803020037), Special Fund of Science and Technology Innovation Strategy of Guangdong Province (Grant No. pdjh2020a0083).

\section{Author's Contributions}

Lin Yunshuo: Conceived and designed the experiments and wrote the paper.

Li Zhen: Conceived and designed the experiments.

Lv Shilei: Analyzed the data.

Huang Heqing and Hu Jiapei: Contributed reagents/materials/analysis tools.

All authors read and approved the final manuscript.

\section{Ethics}

This article is original and contains unpublished material. The corresponding author confirms that all of the other authors have read and approved the manuscript and no ethical issues involved.

\section{References}

Chen, P.F., L. Liu, J.H. Wang, T. Shen and A.X. Lu et al., 2008. Real-time analysis of soil $\mathrm{N}$ and $\mathrm{P}$ with near infrared diffuse reflectance spectroscopy. Spectroscopy Spectral Anal., 28: 295-298. PMID: 18479007

Ding, W.G., J.S. Chen, S. Wu and H.W. Niu, 2011. Research on correlation between visible spectrum and soil fertility factors in semi-arid region of China. Agric. Res. Arid Areas, 29: 150-155.

Li, J., X. Zhang, Y. Yuan and J. Zhang, 2012. Analysis of soil nutrient content based on near infrared reflectance spectroscopy in Beijing region. Trans. Chinese Society Agric. Eng., 28: 176-178. DOI: 10.3969/j.issn.1002-6819.2012.02.031

Li, J., Y. Zuo and J. Zhang, 2007. Design on measuring gauge for soil organic matter content based on reflectance spectra characteristic. Trans. Chinese Society Agric. Machinery, 38: 116-119. DOI: 10.3969/j.issn.1000-1298.2007.08.030
Li, M. and J. Li, 2008. Improved design of soil organic matter content tester based on the reflection spectrum characteristics. Trans. Chinese Society Agric. Machinery, 39: 148-151.

DOI: 10.3969/j.issn.1000-1298.2007.08.030

Li, W., 2011. The structure of Citrus trade in the world and the prospect of citrus export in China in recent years. Agric. Outlook, 6: 51-54.

DOI: 10.3969/j.issn.1673-3908. 2011.06.014

Musadji, N.Y., L. Lemée, L. Caner, G. Porel and P. Poinot et al., 2020. Spectral characteristics of soil dissolved organic matter: Long-term effects of exogenous organic matter on soil organic matter and spatial-temporal changes. Chemosphere.

DOI: 10.1016/j.chemosphere.2019.124808

Pan, W., S. Li, K. Wang, H. Xiao and B. Chen et al., 2010. Monitoring soil nitrogen and plant nitrogen based on hyperspectral of cotton canopy. Cotton Sci., 22: 70-76.

DOI: 10.3969/j.issn.1002-7807.2010.01.011

Satapute, P., M.K. Paidi, M. Kurjogi and S. Jogaiah, 2019. Physiological adaptation and spectral annotation of Arsenic and Cadmium heavy metalresistant and susceptible strain Pseudomonas taiwanensis. Environ. Pollut., 251: 555-563.

DOI: 10.1016/j.envpol.2019.05.054

Song, S.F., J.H. Zhou, X.H. Deng, Y.Y. Zhang and Q. Li et al., 2012. Tobacco soil fertility and suitability for the tobacco production in Dali tobacco areas. J. Hunan Agric. Univ. 38: 16-21. DOI: $10.3724 /$ SP.J.1238.2012.00016

Sophie, T., D. Iryna and D. Nicholas, 2019. Spectral vegetation indices of wetland greenness: Responses to vegetation structure, composition and spatial distribution. Remote Sens. Environ., 234: 111467-111467.

DOI: $10.1016 /$ j.rse.2019.111467

Wamelink, G.W., H.F. Dobben, P. Goedhart and L. Jones-Walters, 2018. The role of abiotic soil parameters as a factor in the success of invasive plant species. Emerg. Sci. J. DOI: $10.28991 /$ esj-2018-01155

Wang, P., J.H. Li and Z.Y. Zhou, 2010. Spectral feature of sugarcane under different soil moisture. J. Water Resources Water Eng., 21: 34-37.

Xie, B., X. Xue, J. Wang and G. Wang, 2004. Spectral characteristics of brown- humid soil and estimation of soil organic matter content by soil reflectivity. Chinese J. Soil Sci., 35: 391-395.

$\mathrm{Xu}, \mathrm{H}$., Y. Gao and K. Wang, 2007. Cokriging interpolation of available $\mathrm{N}$ in paddy soil based on spectral information of rice canopy. Trans. Chinese Society Agric. Eng. 23: 13-17. DOI: 10.3321/j.issn:1002-6819.2007.03.003 
Lin Yunshuo et al. / American Journal of Biochemistry and Biotechnology 2020, 16 (2): 177.183 DOI: 10.3844/ajbbsp.2020.177.183

Yi, S.L., L. Deng, S.L. He, Y.Q. Zheng and J.H. Wang et al., 2011. The near infrared spectrum based models for monitoring $\mathrm{Fe}, \mathrm{Mn}$ and $\mathrm{Zn}$ content of the purple soil in citrus orchard. Scientia Agric. Sinica, 44: 2318-2324. DOI: $10.3864 / j$.issn.0578-1752.2011.11.014

Yi, S.L., L. Deng, S.L. He, Y.Q. Zheng and X. Zhang, 2010. Research on nitrogen content of leaf of Jincheng orange cultivar using visible near infrared spectroscopy model. J. Fruit Sci., 27: 13-17.
Zheng, L., M. Li and H. Sun, 2009. A rapid analysis system of soil parameters based on near infrared spectroscopy. Spectroscopy Spectral Anal., 29: 2633-2636.

DOI: 10.3964/j.issn.1000-0593(2009)10-2633-04 